\title{
Decision Support System for an Art University
}

\author{
Svetlana E. Vecherskaya
}

\begin{abstract}
A prototype of an automated decision support system for creative universities has been developed, which will allow assessing the achievements particularly talented students and identifying the needs in the learning process in order to help organize the educational process in accordance with identified capabilities. Use of a decision support system based on the Bayesian classifier is suggested which will allow to evaluate factors contributing to the progress in teaching students particular techniques, and in perspective to assess the possible resources that will be required to make changes to the learning. The list of specific performance indicators is given. The system should contribute to the formation of the learning plan, taking into account the capabilities of both a group art workshop as a whole, and special needs of an individual to develop, if necessary an individual approach.
\end{abstract}

Keywords : support system, university, performance indicators, learning plan.

\section{INTRODUCTION}

Although creativity has an undeniable value for society, the main forces of researchers and developers are still more concentrated primarily in commercial fields, and as a result, achievements in the field under consideration are not yet significant enough, including the development talent management and decision support techniques. The State is now ready to invest significant funds in basic creative and supplementary education, but the assessing the effectiveness of such investments is difficult due to the complexity of assessing learning outcomes, as well as due to the fact that when evaluating the results of teaching, it is necessary to consider specific indicators of creative activity, mainly qualitative indicators $[6,10]$.

In our time, there is a shift in general consumer needs towards the products of the experience economy, and among consumers of educational services - towards a greater consumption of creative and additional education [13]. The demand for educational services is growing quite rapidly, and the already available qualified teaching staff is not always sufficient. One result is the growth of competition for educational programs in creative specialties [14]. Both at the budget level and at the level of individual creative universities, decisions are required on the investments and the formation of educational programs in accordance with both

Manuscript received on 15 April 2021 | Revised Manuscript received on 24 April 2021 | Manuscript Accepted on 15 July 2021 | Manuscript published on 30 July 2021.

* Correspondence Author

Svetlana E. Vecherskaya*, Institute of Information Systems and Engineering Computer Technologies, Russian New University (RosNOU), Moscow, Russia. Email: s.vecherskaya@bk.ru

(C) The Authors. Published by Lattice Science Publication (LSP). This is an open access article under the CC-BY-NC-ND license (http://creativecommons.org/licenses/by-nc-nd/4.0/) the current tasks of training professional personnel and with the general needs of the cultural development. It is required to conduct a thorough assessment and justification of decisions on the choice of the investment focus, in particular, on the definition of educational profiles and training programs.

The complexity in the formation of systems for making such decisions is primarily due to the fact that it is difficult to clearly determine the expected result of such investment activity, especially when it would lead to the education of a specialist in the creative profession. The decisions taken are inherently political-economic and it is difficult to evaluate them only by financial criteria. In addition, the sphere of human creative activity in itself is difficult to fit into a system of definite frameworks and indicators. A special problem is the identification of particularly talented students of creative specialties. Obviously, geniuses and particularly talented people can not be many, they are just a few among the total mass of students. But society has no right to ignore or to lose these rare specimens. Therefore, a separate task in the formation of programs and standards for creative specialties of educational institutions should be to select such students from the total mass and to create for them the learning environment favorable for the development of their exceptional abilities. Meanwhile, we are not talking about individual training, but about training in parallel with the bulk of students. The formation of training programs as a whole also requires justification based on criteria that reflect the specifics of the field.

The foundations for the application of intelligent machine systems in human resource management have been laid, however there are still many problem domains where tools are needed to transform uncertain and incomplete data into useful knowledge. In general, the approaches of machine learning and hybrid intelligence show their usefulness and effectiveness [5], but their application is still little studied in relation to talent management.

The purpose of this study is to develop a DSS based on a system of performance criteria for evaluating student profiles in order to identify the need to adjust the learning plan in accordance with the students skills and, in particular, to identify talented students. The introduction of such a system should contribute to improving the performance of creative universities, whose distinctive feature is, as a rule, a significant range of the abilities of students - from the level of craft skill to, although rarely, to an extraordinary talent.

\section{METHOD}

There is no universal method that allows determining the dependencies between a variety of heterogeneous indicators at the same time, which is why it is necessary to conduct a comprehensive analysis of the data obtained and identify the dependencies between them.

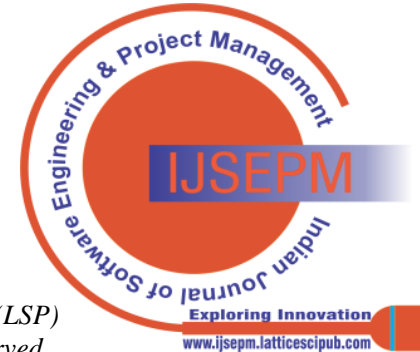


Usually, this is done "manually" in the form of tables, graphs and suchlike, on the basis of which decisions are made, and it is quite difficult to fully automate this process. A common task of automating a decision support system (DSS) that allows you to establish the relationship between the mandatory elements of the learning program and the opportunities for the development of creative abilities of students is advisable to be solved, first at the prototype level.

Methodologically, the work involves the development of a DSS that allows you to establish the relationship between the implementation of the mandatory part of the learning plan and the presence of outstanding abilities, the identification of which is valuable in itself and may also require adjusting the learning plan.

The expected result of the implementation of the DSS is to determine the probability of students having special, outstanding abilities, as well as which indicators of the student profile most determine these abilities. The development is based on a database of students. The database is designed according to the principle of standard human resources records tools. Essential additional data will be the data obtained during the survey and from questioning. For the analysis, numeric and string types of input data are used to describe the characteristics of objects. The requirement for the independence of variables is met. Fuzzy classes are used as output data, so the degree of belonging of the object to each class is determined. Within the framework of this work, it gives the probability with which a particular student can be classified as a particularly talented group. Data Mining technology is used to obtain data. To create a system, one can use the Visual Studio software development environment using the Windows Form Application and standard Data Grid View objects to display information in tabular form.

The problem under consideration is related in a way to talent management. However, talent management is originally much more a management methodology, but not a decision support technique, especially in conditions of high uncertainty of the result typical for creative specialties. The main objective of traditional talent management is to capture the right talent for a given position. The ultimate goal is to manage employees and maximize their productivity and performance.

Talent management in commercial activities is well-developed both in theory and in practice [9, 11], meanwhile there are very few studies devoted to the topic of talent training in educational institutions [15].

Existing talent management software allows you to automate the monitoring of certain processes of the employee's life cycle in the enterprise. Depending on the established evaluation criteria, these products are more or less applicable to career and trainings planning. There are several proven solutions: IBM Talent Management, monday.com, Oracle HCM Cloud, iCIMS Talent Acquisition, TalentSoft, Zoho Recruit [17]. Russian software developers have some similar products. However, according to the "1C company", such management systems as "1C: management by goals and KPIs" can be applied to the organization of process management in a university only for supporting administrative processes [1]. Nevertheless, software products for Talent management are created on the basis of the $1 \mathrm{C}$

\section{platform [16].}

The complexity of adapting existing software products for talent management to administrating the essential content of the educational process at the university is due to the fact that management in the commercial sector is based on achieving a certain economic or, in a narrower sense, of financial results, while it is hardly possible to measure in financial terms such results as, for example, writing a picture or creating a piece of music, until these creations are commercialized. Assessment of the competence and level of training of a student based on reference indicators systems does make sense only for teaching basic skills, but is practically inapplicable to the assessment and even more so to the formation of a learning profile for students with outstanding abilities and results..

\section{REVIEW CRITERIA}

In most cases, DSSs for both enterprise talent management and for the success assessment in the learning process are based on the KPI methodology [3, 6, 10, 12]. The complexity of the assessment of non-commercial activities using KPI approach was emphasized in $[18,19]$. The main problem is the choice of evaluation criteria, the actual result and performance indicators.

The software manufacturer Spiders Strategies offers a detailed list of KPI educational services [4]. Classifying of the indicators would reveal interesting patterns. Thus, almost three-quarters of the indicators will be financial and organizational KPIs (37\%) and KPIs of headcount, attendance, and academic performance (34\%, note that this is about an assessment of academic performance, but not an assessment of results that exceed the sufficiency level). KPIs that allow assessing the special achievements of individuals or the University as a whole are only $14 \%$.

The problem of forming a set of criteria for identifying talents among the entire mass of students of creative specialties has been of interest to few researchers since quite long ago. Thus, Meier published a series of works in which the author tried to determine the parameters for assessing creative talent in the visual arts [7, 8]. The author's approach is based on determining correlations between indicators of creative (art) intelligence and academic performance.

The overall goal of teaching students in creative specialties, as well as of teaching students in general, should be to train personnel in accordance with the massive demand of schools and industries. To track and evaluate the results of all students, you can use, for example, a group set of indicators of academic performance from [4]. Additional metrics need to be introduced to scoring systems to identify special talent. If an IT system is used to make decisions about the educational process conduct, the dashboard monitoring mode would be useful [1]. Monitoring should identify and highlight the part of students for whom special options for the learning plan are preferable in accordance with their talents and requirements.

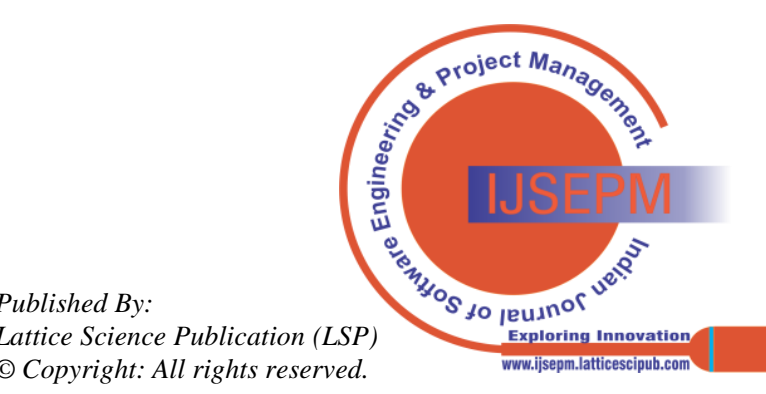


Some Russian art universities currently apply a flexible approach to the formation of the learning and training plan, which is based on the training all students in various artistic techniques, but the number of hours for each of them may vary. Normally there is a lot of "manual tuning" for general headcount and academic performance indicators, but the approach can be more effective by implementing a DSS based on the same criteria and adding some indicators of outstanding results. The task of identifying and developing approaches to working with students with any special talents should be solved through a special DSS. The configuration of such a system can be done in any standard form, for example that of Bayesian classifier and using machine learning [2].

At the data preparation stage, a set of student data is created. The personnel accounting software scheme assumes the presence of lists of departments (workshops), lists of students, headcounts, keeping records of personnel information in performance indicators with the ability to enter additional information on the employee in the required data format. The table "Students" stores personal data of students which may be necessary for analysis (First name, Last name; Date of birth; Previous profile education; Obtainment of a diploma in an art specialty; Year of obtaining a previous diploma in an art specialty; Obtainment of awards of creative competitions; Participation in art exhibitions / dates). The hybrid database used also contains "Profiles" and "Performance" fact tables, as well as relational database dictionaries. The data in the "Profiles" table are entered based on the results of interviews with students in the form of a questionnaire. The "Performance" table is formed based on the evaluation of the corresponding performance indicators.

The "Performance" table stores data about the grades received by the student in the learning process, as well as on the obtaining and degree awards. Analysis of the results for the previous periods makes it possible to track the development of the student as a whole, and separately in the development in creative specialties, which in turn gives more complete information about the student skills and abilities for subsequent analysis.

The "Profiles" table stores data on the assessments of the indicators of student achievement and includes the date of the assessment: the date of the evaluation; name of the student assessed; overall, the average performance; average performance in creative disciplines; record of attendance; the level of interest in studies; availability of scholarships; the degree of involvement in creative competitions within the University; the degree of involvement in creative competitions outside of the University; the degree of involvement in the exhibition process; the level of awards in creative contests; the degree of the need for increased training in the creative professions. All ratings stored in the "Profiles" table range from 0 to 2 points: 0 -bad or no; 1 -satisfactory; 2-good or yes.

A generalized model of the knowledge acquisition process for a database is built on the basis of association rules and a Bayesian classifier (Figure 1). The knowledge acquisition process involves the implementation of several stages of the Knowledge discovery databases (KDD) technology together with Data Mining methods to build a descriptive model.

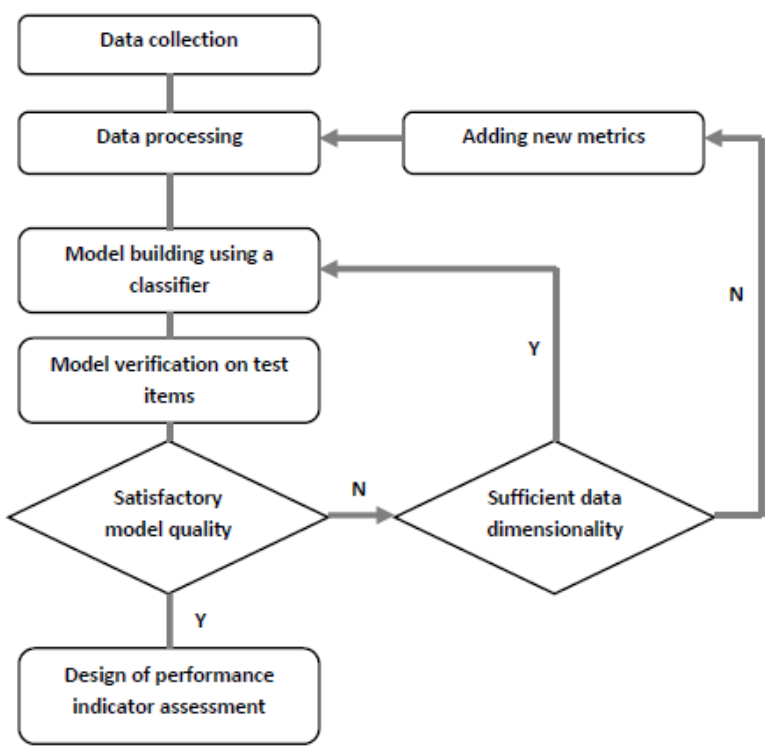

Fig. 1.Knowledge acquisition model.

In the course of the work, the training and testing sample is determined. First, it is necessary to extract data on students with outstanding creative results (awards, grants, diplomas of exhibition, the highest scores in a creative specialty) and the rest of the students. These data are combined in one list and divided into training and test samples. The data in the database is stored in a random order, therefore, the selection in the training sample can be carried out, for example, according to the principle: three employees in the training sample, we skip one. The test sample should consist of all students, including those in the training sample.

Objects of both classes (regular and outstanding) are required to train the classifier. The result of using the classifier on the test sample will be an indicator of the probability of the need to single out a student as especially talented and the priority of working with this student in the development of specific creative skills.

The training of the classifier takes place in several stages, which differ in the analyzed characteristics. The input data have different types, different ranges, and therefore it is impossible to train the classifier in all characteristics in the same way. The process is conveniently divided into stages. At the initial stage, training is conducted (Figure 2), taking into account the development of the student (performance indicators, special indicators for creative specialties). This is followed by training that takes into account the stability of average indicators (the student may not be distinguished by outstanding results, but in general is characterized by high scores in general training); it is calculated over how many periods the student shows a certain average level of overall performance. The next stage is learning that takes into account the achievements of other students at the relevant stage of education. The learning taking into account the points awarded during regular assessment of indicators completes the learning process.

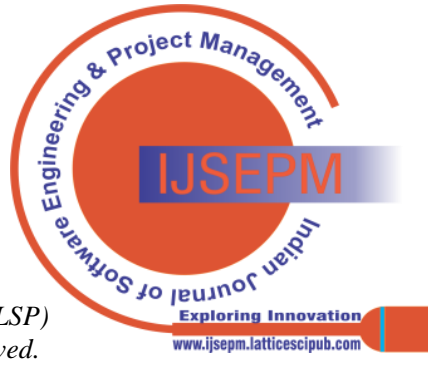


It is reviewed retrospectively so that it is possible to track what points were received by students who then demonstrated any outstanding achievements.

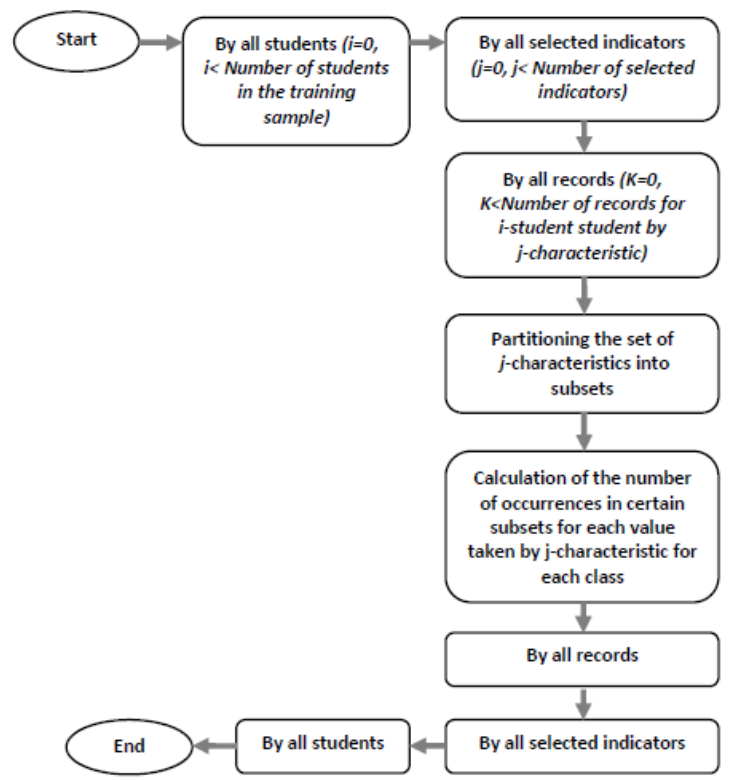

Fig. 2.Algorithm for training the classifier.

The same steps are taken when testing the classifier on test data. At each of the stages, for each student it is determined to which time interval the value of the current indicator belongs. Then the estimates of the student's belonging to both classes are calculated for the given value of the indicator using the Bayes formula. After all the student's performance indicators are taken into account, the assessments of the student's belonging to the classes are translated into the a priori probability of the student's belonging to the "outstanding" class. Algorithm for testing the classifier is shown in Figure 3.

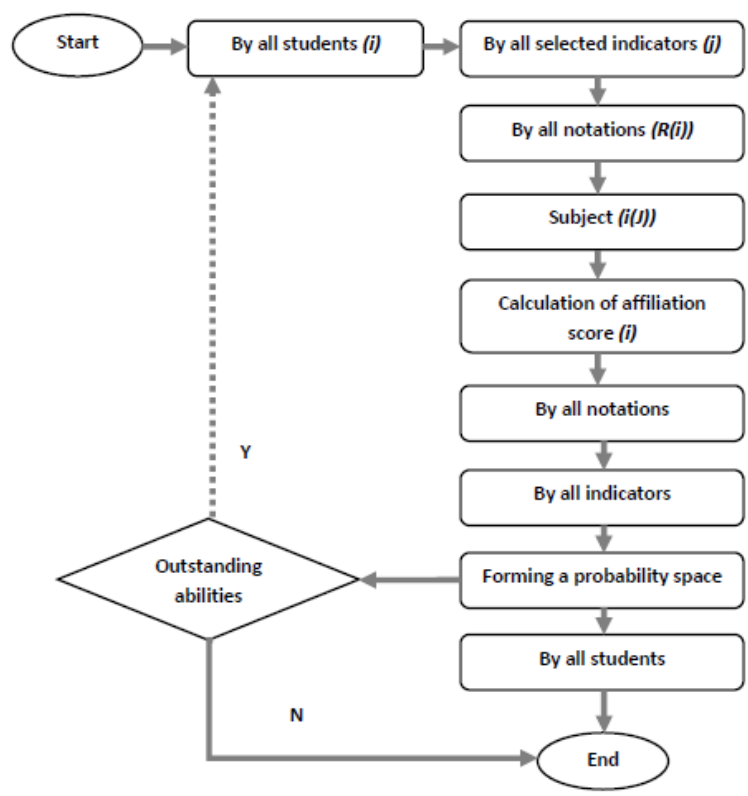

Fig. 3.Algorithm for testing the classifier.

In the working mode, the system shows a list of all students with their personal data, and the calculated probability of belonging to a group of particularly talented. Those students whose probability of special abilities exceeds the specified value are highlighted with a marker. Based on the results of the work of the system, the university decides on the need to select the marked students for enhanced training in any creative specialties, regardless of the results of overall academic performance. For the selected students, the system contains information about its development in the learning process and the results of its questionnaire survey (Figure 4).

\begin{tabular}{|l|l|l|r|r|r|r|}
\hline $\begin{array}{l}\text { Date of } \\
\text { survey }\end{array}$ & \multirow{2}{*}{ Name } & Workshop & Middle overall score & Attendence & Contests & Awards \\
\hline 01.02 .2019 & & 1 & 2 & 0 & 0 \\
\hline 01.04 .2019 \\
\cline { 1 - 7 } & & Easel graphics D & 06.2019 \\
\cline { 3 - 7 } & & Easel graphics D & 1 & 1 & 2 & 1 \\
\cline { 2 - 7 } & Easel graphics D & & 1 & 0 & 1 \\
\cline { 2 - 7 } & & & & & & \\
\hline
\end{tabular}

Fig. 4.Example of Student assessment results.

Analysis of student development data tables, in particular, can give the following options. The marker in the "Middle overall score" column indicates that the student's academic performance is below the workshop average. The marker in the "Awards" and "Contests" ("Contests" includes participation in competitions for exhibitions) columns indicates that an individual approach to teaching creative specialization is a priority for this student. Additional information can be taken from the "Profiles" table. In this case, the marker in the "Creative discipline" column will mean that it is preferable for this student to strengthen training in the direction of the specified discipline, and the marker in the "Prior education" column means that for this student it is possible to reduce the requirements for basic disciplines and practices and is preferable emphasis on advanced learning training.

Thus, Figure 4 shows that the student has obvious problems with overall academic performance, but demonstrates certain achievements in professional creative activity. Most likely, such a student requires an individualized approach to the formation of his learning plan with an emphasis on the development of creative skills.

The key point would be the introduction of metrics characterizing students special achievements into the system of criteria. In the prototype under consideration, such key indicators as participation in contests and awards were used. In the general case following indicators can be recommended: results of participation in creative competitions, participation in exhibitions with reference to exhibition level, membership in creative unions, receipt and degree of awards, novelty of techniques used, novelty of the use of art materials, uniqueness of the subject, uniqueness of coloristics, novelty of the stylistic solution, principles of composition. The list is not exhaustive and can be expanded depending on the specifics of the art field. Methods of expertise in the field of intellectual property may be recommended as suitable for detecting and automating the identification of novelty and uniqueness, as in [20].

Lattice Science Publication (LSP)

(C) Copyright: All rights reserved.

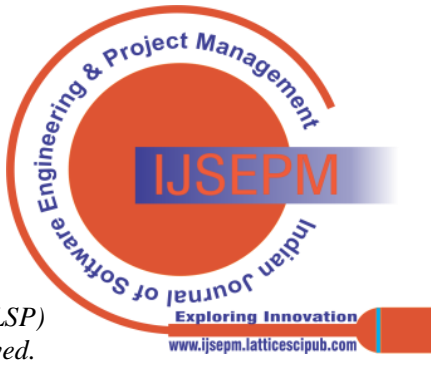


Thus, even if a student is performing average or below average success in general academic performance, but has any special talent in any art specialty, the system should identify him as promising and indicate an eventual need for certain changes in the learning. In general, the system should contribute to the formation of the learning plan, taking into account the capabilities of both a group art workshop as a whole, and special needs of an individual to develop, if necessary an individual approach.

\section{CONCLUSION}

DSS was implemented as a prototype, with only a few of the proposed list of performance indicators used for students assessment. In a similar way, other indicators proposed to assess the creative abilities of students can be included in the algorithm. The given approach shows that the identifying the needs of talented individuals in the learning process in a creative university and organizing the educational process in accordance with their capabilities and needs can be automated using computer decision support solutions that include specific performance indicators for evaluating creative results. It is important to turn on the assessment system not at the end, but during the learning process, in a dashboard mode, in order to solve two key tasks: to identify special talents and to build the learning programs in such a way as to ensure the maximum identification and development of creative skills. The system should contribute to the formation of the curriculum, taking into account the capabilities of both the group art workshop as a whole and the special needs of the individual in order to develop, if necessary, an individual approach. A further work remains to be done to analyze the feasibility of assessing the economic relevance of applying the appropriate organizational solutions. A similar approach can be proposed for other creative educational institutions.

\section{REFERENCES}

1. 1C: Management by goals and KPI https://solutions.1c.ru/catalog/kpi/features

2. Asuncion A., Newman D. UCI machine learning repository: Tech. rep.: University of California, Irvine, School of Information and Computer Sciences, 2007.

3. Davidsson P., Honig B. The role of social and human capital among nascent entrepreneurs. Journal of Business Venturing. 2003. Vol. 18 No. 3, Pp. 301-331. [CrossRef]

4. Educational Kervices Available at https://www.spiderstrategies.com/kpi/industry/educational-services/

5. Jantan H., Hamdan A.R., Othman Z.A. Intelligent Techniques for Decision Support System in Human Resource Management. Available at: https://www.researchgate.net/publication/221908325

6. Kennedy C. 5 minute read KPI Examples in Higher Education. Posted on May 2010. Available at: https://blogs.sap.com/2010/05/03/kpi-examples-in-higher-education/

7. Meier, N. C. A measure of art talent. Psychological Monographs, 1928 39(2), p.184-199. Available at https://psycnet.apa.org/record/2011-15687-020. [CrossRef]

8. Meier N.C., McCloy W. An instrument for the study of creative artistic intelligence. Psychological Monographs, 1936. Vol 48(1). p.164-172. [CrossRef]

9. Metrics for Excellence. Ivan Allen College of Liberal Arts. Available at: https://internal.iac.gatech.edu/poa/1/d

10. Moetaz J. S. The Impact of Key Performance Indicators (KPIs) on Talent Development. International Journal of Recent Research in Commerce Economics and Management (IJRRCEM) Vol. 3, Issue 4, p.50-57, Month: October - December 2016, Available at: https://www.researchgate.net/publication/311986170_The_Impact_of_ Key_Performance_Indicators_KPIs_on_Talent_Development
11. Parmenter D. Key Performance Indicators: Developing, Implementing and Using Winning KPI's. New Jersey, USA: John Wiley \& Sons, inc., 2007.

12. Peterson E.T. The Big Book of Key Performance Indicators, USA, Web analytics demystified, January 1, 2006.

13. Pine J., Gilmore J. The Experience Economy, Harvard Business Schoo Press, Boston, 1999

\section{AUTHORS PROFILE}

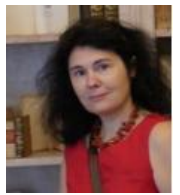

Svtlana Vecherskaya, $\mathrm{PhD}$, docent of the Institute of Information Systems and Engineering Computer Technologies of Russian New University, author of about 40 scientific publications in the fields of management, informatics and natural sciences.

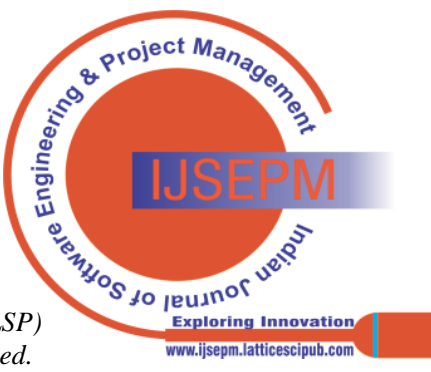

